\title{
Influence of Constituent Materials on the Impact Toughness and Fracture Mechanisms of Hot-Roll-Bonded Aluminum Multilayer Laminates
}

\author{
C.M. CEPEDA-JIMÉNEZ, P. HIDALGO, M. POZUELO, O.A. RUANO, \\ and F. CARREÑO
}

Two aluminum multilayer laminates have been processed by hot roll bonding following similar processing paths. The first one is constituted by alternated Al 2024 and Al 1050 layers (ALH19) and the second one by alternated Al 7075 and Al 1050 layers (ADH19). The influence of the constituent materials in the multilayer laminates both during the processing at high temperature and during the subsequent mechanical characterization has been analyzed. The mechanical behavior of the as-received materials at the processing conditions has been characterized by hot torsion. Multilayer laminates have been tested at room temperature under impact Charpy tests, three-point bend tests, and shear tests on the interfaces. The relative toughness increase compared to the constituent materials was much higher for the ADH19 laminate based on the highstrength Al 7075 alloy than for the ALH19 laminate. This is attributed to the different fracture mechanism.

DOI: $10.1007 / \mathrm{s} 11661-009-0069-\mathrm{x}$

(c) The Minerals, Metals \& Materials Society and ASM International 2009

\section{INTRODUCTION}

IN recent years, metallic multilayer composites have received attention due to their striking mechanical, electrical, and magnetic characteristics. ${ }^{[1,2]}$ Through an adequate design of these structures and taking into account the responsible mechanisms of the improved failure behavior as compared to those of the individual components, it is possible to tailor materials to the requirements of a particular application. ${ }^{[3]}$

The most common method used in industry to manufacture these laminates is roll bonding. In this process, two or more strips of similar or dissimilar alloys are rolled together for several passes. ${ }^{[4-6]}$ The rolling process is capable of producing the high interfacial pressures required to cause strong adhesion of the components by complex interface development. ${ }^{[7]}$ A metallurgical bond between the alloys then develops at the interface during the rolling process. Furthermore, the bond quality is influenced by a number of interdependent parameters such as temperature, pressure (determined by the degree of reduction), contact time (roll speed),${ }^{[8]}$ and the mechanical behavior of the constituent materials to be bonded at the processing temperature.

Multilayer composite laminates based on aluminum alloys have been developed by hot roll bonding,

C.M. CEPEDA-JIMÉNEZ, Ph.D. Researcher, P. HIDALGO, Ph.D. Student, O.A. RUANO, Professor, and F. CARREÑO, Staff Researcher, are with the Department of Physical Metallurgy, CENIM, CSIC, 28040 Madrid, Spain. Contact e-mail: cm.cepeda@ cenim.csic.es M. POZUELO, Postdoctoral Researcher, is with the Department of Materials Science and Engineering, University of California, Los Angeles, CA 90095-1595.

Manuscript submitted May 29, 2009.

Article published online October 29, 2009 resulting in materials of improved impact toughness. ${ }^{[5,9]}$ In hot-rolled aluminum multilayer laminates, bonding occurs by fracturing of the surface alumina on the layers and then flowing the aluminum through the fractured alumina regions. Consequently, the cracking of the alumina coating allows metal-metal contact and roll bonding to take place. The interface, therefore, is a combination of oxide fragments and bonded areas of "extruded" aluminum. ${ }^{[9]}$

In the present work, two multilayer materials based on different constituent aluminum alloys have been processed by hot roll bonding. The Al 2024 alloy and Al 1050 constitute the first of them and the second one is based in a high-strength Al 7075 alloy and Al 1050. The Al 2024 and Al 7075 alloys have been selected due to their high strength and their extensive application in commercial aircrafts. On the other hand, the high ductility of the Al 1050 favors bonding between the aluminum layers during processing. Therefore, the objective of this study is to analyze the influence of the constituent materials on the fracture mechanisms and the improved impact toughness of roll-bonded laminates processed by similar strain paths.

\section{EXPERIMENTAL PROCEDURE}

\section{A. Materials and Processing}

The aluminum alloys used in the present study were rolled Al 7075-T6 and Al 2024-T3 sheets $2 \mathrm{~mm}$ in thickness (termed "D" and "L," respectively), and A1 $1050-\mathrm{H} 24$ sheets (termed "H") $0.5 \mathrm{~mm}$ in thickness. Samples of $60 \times 150 \mathrm{~mm}^{2}$ were used. The composition of the alloys in atomic percent is included in Table I and 
Table I. Chemical Composition of As-Received Aluminum Alloys (Atomic Percent)

\begin{tabular}{lccccccccc}
\hline Alloy & $\mathrm{Si}$ & $\mathrm{Fe}$ & $\mathrm{Cu}$ & $\mathrm{Mn}$ & $\mathrm{Mg}$ & $\mathrm{Cr}$ & $\mathrm{Zn}$ & $\mathrm{Ti}$ & $\mathrm{Ni}$ \\
\hline $7075(\mathrm{D})$ & 0.05 & 0.04 & 0.74 & 0.01 & 2.89 & 0.13 & 3.05 & 0.04 & -14 \\
$2024(\mathrm{~L})$ & 0.07 & 0.04 & 2.46 & 0.21 & 1.26 & 0.04 & 0.14 & 0.02 & 0.06 \\
$1050(\mathrm{H})$ & 0.12 & 0.21 & $<0.005$ & 0.02 & 0.01 & $<0.010$ & $<0.005$ & $<0.010$ & - \\
\hline
\end{tabular}

Table II. Mechanical Properties of As-Received Aluminum Alloys

\begin{tabular}{lcccc}
\hline Alloy & $\begin{array}{c}\text { UTS* } \\
\text { (MPa) }\end{array}$ & $\begin{array}{c}\text { YS* } \\
\text { (MPa) }\end{array}$ & HV & $\begin{array}{c}\text { Elongation* } \\
\text { (Pct) }\end{array}$ \\
\hline 7075-T6 (D) & 545 & 475 & 188 & 8 \\
2024-T3 (L) & 457 & 333 & 138 & 16 \\
$1050-$ H24 (H) & 136 & 128 & 44 & 7 \\
\hline
\end{tabular}

Note: $\quad$ UTS $=$ ultimate tensile strength; YS = yield $\quad$ stress; $\mathrm{HV}=$ Vickers hardness; $\mathrm{T} 6=$ solution treating followed by quenching and, finally, peak age hardening; T3 = solution treating followed by quenching, cold working, and, finally, natural aging; and $\mathrm{H} 24$ = work hardening followed by partial annealing $\left(240{ }^{\circ} \mathrm{C}\right)$.

* Data provided by the alloy maker from tensile tests.

some mechanical properties are summarized in Table II. The as-received sheets were cleaned with acetone. Two stacks of multilayer composites were considered. The stacks were constituted by ten layers of Al 2024 alloy (L) or Al 7075 alloy (D) and nine layers of Al $1050(\mathrm{H})$ stacked alternately, building a bundle $\sim 25 \mathrm{~mm}$ in thickness and referenced in this work as ALH19 and ADH19, respectively.

The two stacked aluminum materials were welded by tungsten inert gas at their edges to avoid oxygen penetration and delamination during processing, and then hot rolled at $465^{\circ} \mathrm{C}$ in several passes without lubrication. The rolls were $130 \mathrm{~mm}$ in diameter and the rolling speed was $346 \mathrm{~mm} / \mathrm{s}$. The rolling direction (RD) was parallel to the RD of the as-received sheets.

Rolling was carried out similarly in both laminates in five cycles of three passes and an approximately 4 to 8 pct reduction per pass, with the samples being reheated at $465{ }^{\circ} \mathrm{C}$ between every cycle. Finally, the total thickness reduction for the ALH19 laminate was $\varepsilon=0.96$ according to the von Mises criterion (corresponding to a thickness reduction of approximately 2.3 to 1) and $\varepsilon=0.85$ (reduction 2.1:1) for the ADH19 laminate. The thickness of the aluminum layers was approximately 910 and $250 \mu \mathrm{m}$ for the Al 2024 alloy and the Al 1050, respectively, in the ALH19 laminate, and 990 and $270 \mu \mathrm{m}$ for the Al 7075 alloy and the Al 1050, respectively, in the ADH19 laminate. Therefore, the total strain was slightly higher for the ALH19 laminate than for the ADH19 laminate, despite similar processing paths that were carried out for both laminates.

Due to the high temperatures employed during the processing, it was necessary to carry out a heat treatment after hot rolling. This treatment improves the mechanical properties of the high-strength Al 7075 and $\mathrm{Al} 2024$ alloys included in the laminate materials in order to reach the maximum hardness by precipitation hardening. The heat treatment considered for these alloys was the $\mathrm{T} 6$ temper. This heat treatment for the $\mathrm{Al}$
7075 alloy involved solution treating at $465{ }^{\circ} \mathrm{C}$ for 30 minutes, followed by rapid quenching in water and finally age hardening at $135{ }^{\circ} \mathrm{C}$ for 14 hours. The T6 temper carried out for the Al 2024 alloy involved solution treating at $490{ }^{\circ} \mathrm{C}$ for 30 minutes, followed by rapid quenching in water and finally age hardening at $160{ }^{\circ} \mathrm{C}$ for 6 hours.

\section{B. Microstructures}

The microstructure of the Al 1050 constrained between the high-strength aluminum alloys (Al 7075 and Al 2024) in the multilayer laminates was observed by backscattered electrons in a scanning electron microscope (SEM) JEOL* JSM 6500F with a field emission

*JEOL is a trademark of Japan Electron Optics Ltd., Tokyo.

gun. Additional information was obtained by the electron backscattering diffraction (EBSD) technique, also in the SEM equipped with a fully automatic EBSD attachment (HKL Technology, Oxford Instruments, Abingdon, Oxfordshire, UK) operating at an accelerating voltage and working distance of $20 \mathrm{kV}$ and $15 \mathrm{~mm}$, respectively. The corresponding data processing was carried out using HKL Channel 5 software (Oxford Instruments, Abingdon, Oxfordshire, UK). Microstructural investigations of the Al 1050 alloy layers were conducted on the midthickness regions of the laminate material. A low-angle grain boundary (LAB) was defined by a misorientation between adjacent grains of 2 deg $<\theta<15$ deg and a high-angle grain boundary (HAB) was defined by $\theta>15 \mathrm{deg}$. The HAB and LAB are shown as black and white lines, respectively, on the maps. Specimens were mechanically polished and then electropolished in a 30 pct nitric acid solution in methanol at $-28^{\circ} \mathrm{C}$ and $15 \mathrm{~V}$ to produce a strain-free surface.

The chemical compositions across the laminate interfaces were examined by an electron probe microanalyzer (Oxford Inca, Oxford Instruments, Abingdon, Oxfordshire, UK) operating at $15 \mathrm{kV}$.

\section{Mechanical Tests}

\section{Microhardness test}

Microhardness measurements were carried out around the laminate interfaces with a Vickers indenter (Matsuzawa Seiki MHT-1, Tokyo, Japan) under loads of $100 \mathrm{~g}$ during 15 seconds. Vickers microhardness values $v s$ distance to the interface were represented in order to observe the hardness gradient across the interface. The distance to the interface was measured from the indentation center using image analysis software. 


\section{Torsion tests}

Hot torsion tests were conducted on the as-received Al 2024 and Al 7075 alloys. The hot torsion machine, SETARAM 7MN (SETARAM Instrumentation, Caluire, France), has been described elsewhere. ${ }^{[10]}$ The range of deformation parameters of the torsion test covered the conditions used during hot rolling. The torsion samples were machined so that the gage length coincided with the RD. Samples 17-mm gauge length and $3 \mathrm{~mm}$ in radius were torsioned to fracture at a constant temperature and strain rate. The samples were introduced in a silica tube with an argon inlet, to ensure protection against oxidation and to minimize adiabatic heating, and were heated by a high-frequency induction furnace. The temperature during the torsion test was measured by a two-color pyrometer. The temperature range was $280{ }^{\circ} \mathrm{C}$ to $465{ }^{\circ} \mathrm{C}$ and the strain rate was $3.3 \mathrm{~s}^{-1}$ (during the rolling processing of the laminates, the strain rate varied between 1.9 and $3.6 \mathrm{~s}^{-1}$ ). All tested samples were first heated to $465^{\circ} \mathrm{C}$ in 10 minutes and held for 15 minutes at this temperature, similar to the roll-bonding processing of the multilayer laminates. Furthermore, the samples were cooled in 2 minutes to the testing temperature and then were tested. The torsion tests provided directly the curves of torque, $\Gamma$, $v s$ the number of turns, $N$. The effective stress $(\sigma)$, the effective strain $(\varepsilon)$, and strain rate $(\dot{\varepsilon})$ were calculated by means of the following relationships: ${ }^{[11]}$

$$
\sigma=\frac{\Gamma \sqrt{3}}{2 \pi R^{3}}\left(3+m+\theta^{\prime}\right), \quad \varepsilon=\frac{2 \pi R N}{L \sqrt{3}}, \quad \dot{\varepsilon}=\frac{2 \pi R \dot{N}}{L \sqrt{3}}
$$

where $R$ is the sample radius, $L$ is the gage length, $m$ is the strain rate sensitivity, and $\theta^{\prime}$ is the work-hardening exponent:

$$
m=\left.\frac{\partial \ln \Gamma}{\partial \ln \dot{\varepsilon}}\right|_{\varepsilon, T}, \quad \theta^{\prime}=\left.\frac{\partial \ln \Gamma}{\partial \ln \varepsilon}\right|_{\dot{\varepsilon}, T}
$$

\section{Charpy test}

$2 \mathrm{~mm}$ V-notched Charpy testing samples were machined with $10 \times 10 \times 55 \mathrm{~mm}^{3}$ dimensions. The tests were conducted in ALH19-T6 and ADH19-T6 laminates and in as-received monolithic aluminum alloy plates in the same temper as the as-received sheets used in this study. The samples were tested in the crack arrester orientation. This orientation for the monolithic as-received materials corresponds to a configuration in which the notch tip is parallel to the rolling plane and the RD. For the laminate materials, the notch was machined to end at an individual layer of the test sample such that the crack front advances through each layer interface sequentially during the test. Charpy tests were performed with a pendulum impact tester using a maximum capacity of $294 \mathrm{~J}$. The velocity of the striker in the impact instant was $5.4 \mathrm{~m} / \mathrm{s}$ and the strain rate was approximately $1.5 \times 10^{2} \mathrm{~s}^{-1}$. Three samples of each material were tested.

\section{Three-point bend test}

The influence of the interfaces and the rolling strain on the fracture mechanisms of the two multilayer laminates was determined by the three-point bend test, using V-notched Charpy samples $\left(10 \times 10 \times 55 \mathrm{~mm}^{3}\right)$ in the crack arrester orientation. The bend test was performed using a Servosis universal test machine (Servosis S.A., Fuenlabrada, Spain) under displacement control at a rate of $0.04 \mathrm{~mm} / \mathrm{s}$, with load and time recorded by the data acquisition program. At least two samples for each laminate were used to collect data. A representation of raw data, load vs displacement, was used in order to characterize the mechanical response to layer fracture and crack propagation across the composite laminates, which is an assessment of damage tolerance. The fracture surfaces of selected samples were examined by SEM to evaluate the deformation and fracture micromechanism and any interlayer debonding.

\section{Shear test}

The bonding of aluminum layers is a crucial step in the present process in order to obtain high-integrity structural materials. The interface strength was measured by shear tests in a universal test machine (crosshead speed of $0.005 \mathrm{~mm} / \mathrm{s}$ ) using samples of approximate dimensions of $10 \times 10 \times 3 \mathrm{~mm}^{3}$. The tests were performed by clamping the sample between two metal supports. The interface to be tested is located just outside the border of the tool and parallel to the load direction. A square punch at a given gap distance is then used to apply the shear load until failure of the interface. A scheme of the shear test performed was shown elsewhere. ${ }^{[12]}$ The shear stress $\tau$ and the shear strain $\gamma$ are given by the expressions: ${ }^{[13]}$

$$
\tau=\frac{p}{a e}, \quad \gamma=\tan (\alpha)=\frac{d}{l_{\text {gap }}}
$$

where $a$ is the initial width of the sample, $e$ is the initial thickness, $p$ is the force applied on the sample, $d$ is the midspan displacement of the sample, $\alpha$ is the shear angle, and $l_{\text {gap }}$ is the distance between the supports and the mobile punch, corresponding to $0.35 \mathrm{~mm}$ in this study.

\section{RESULTS}

\section{A. Microstructure}

Figure 1(a) shows the microstructure of the asreceived $\mathrm{Al} 1050$ in the $\mathrm{H} 24$ condition, which was work hardened followed by partial annealing at $240{ }^{\circ} \mathrm{C}$. The as-received material presents an equiaxed (sub)grain structure with an average (sub)grain size of 2 to $3 \mu \mathrm{m}$. In addition, insoluble iron-rich intermetallic particles were randomly distributed in the as-received sheet and ranged in size between 0.5 and $5 \mu \mathrm{m}$. The EBSD map of the asreceived Al 1050 at lower magnification (Figure 1(b)) shows a bimodal microstructure highlighting a main lamellar structure composed of large grains elongated in the RD with a fine substructure (2 to $3 \mu \mathrm{m}$ ) within the grains. Additionally, small aggregates of highly misoriented grains can be observed along the original elongated grain boundaries. Thus, the distribution of spacing between the HABs on the as-received Al 1050 

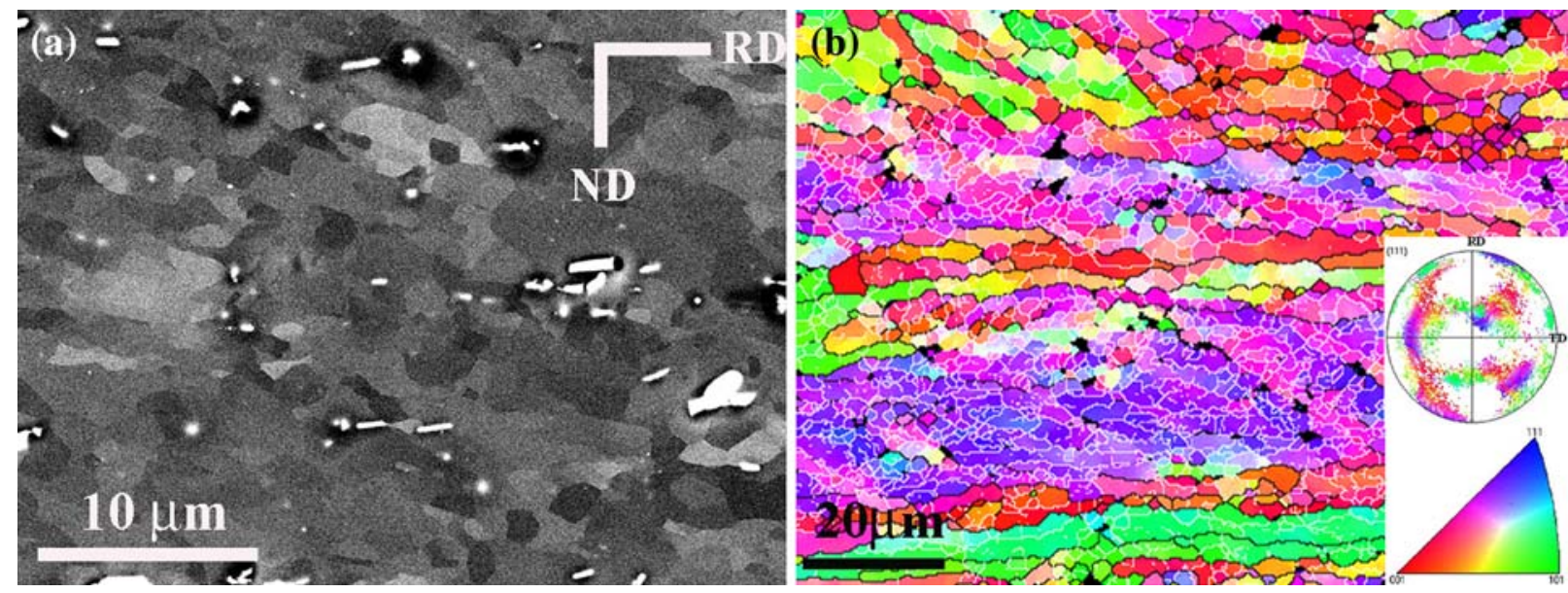

Fig. 1-(a) Backscattered electron micrograph and (b) EBSD map showing the microstructure of the as-received Al 1050-H24 (H) in the ND-RD section.

presents a bimodal structure with large grains 15 to $20 \mu \mathrm{m}$ in thickness and small grains 2 to $3 \mu \mathrm{m}$ in thickness. The EBSD map has been color coded according to the inverse pole figure shown in the inset, representing the crystallographic orientations parallel to the normal direction (ND). The (111) pole figure corresponding to the as-received Al 1050 (inset of Figure 1(b)) shows a $\beta$-fiber ideal texture in rolled fcc metals, comprising variants of ideal orientation components $\{112\}\langle 111\rangle$ (copper), $\{123\}\langle 634\rangle$ (S3), and $\{110\}\langle 112\rangle$ (brass) ${ }^{[14]}$

Figure 2 shows backscattered electron micrographs of the Al 1050 included in the ALH19 (Figures 2(a) and (b)) and ADH19 (Figures 2(c) and (d)) laminates before (as-rolled) (Figures 2(a) and (c)) and after (Figures 2(b) and (d)) the T6 heat treatment. Figure 2(a) corresponding to the Al 1050 in the as-rolled ALH19 laminate shows fine equiaxed subgrains with sharp grayscale contrast. This subgrain microstructure very much resembles the original microstructure of the as-received Al 1050 (Figure 1(a)). In contrast, Figure 2(c) corresponding to the Al 1050 in the as-rolled ADH19 laminate presents a coarser substructure. After T6 treatment, the Al 1050 microstructure in the ALH19 laminate (Figure 2(b)) still shows fine equiaxed subgrains $(2$ to $3 \mu \mathrm{m})$, although some coarser $(\sim 10 \mu \mathrm{m})$ subgrains dispersed randomly throughout the microstructure were also observed. Figure 2(d), corresponding to $\mathrm{Al} 1050$ in the ADH19-T6 laminate, shows that during the T6 thermal treatment, abnormal subgrain growth occurred and a number of subgrains grew rapidly and discontinuously to sizes over $50 \mu \mathrm{m}$. Occasionally, clusters of smaller subgrains were still found between the rapidly coarsened grains, as shown in Figure 2(d).

In addition, Figure 3 presents EBSD maps of the $\mathrm{Al}$ 1050 in the as-rolled ALH19 (Figure 3(a)) and in the as-rolled ADH19 (Figure 3(b)) laminates at lower magnification than the previous backscattered electron micrographs (Figure 2). The EBSD map corresponding to the Al 1050 in the as-rolled ALH19 laminate, hence constrained between Al 2024 layers (Figure 3(a)), shows a slight increase in the subgrain size after processing, although a well-defined and equiaxed LABs microstructure (subgrains) is still clearly observed. The as-received lamellar structure has disappeared. The variation in the color gradient within the grains indicates that the microstructure is made up of dislocation structures and cells with LABs. In contrast, the EBSD map corresponding to the Al 1050 constrained between the Al 7075 alloy in the as-rolled ADH19 laminate (Figure 3(b)) reveals that cells or subgrains formed during the deformation are arranged in parallel bands having an angle of approximately 35 to $45 \mathrm{deg}$ with the RD. Each band in this regular array actually consists of dislocation cells linked up along the band direction. Therefore, the Al 1050 presents a finer (sub)grain microstructure in the as-rolled ALH19 laminate than in the as-rolled ADH19 laminate, which is constituted by the higher-strength Al 7075 alloy. In addition, a change in texture of the Al 1050 layers for both laminates can be observed, indicating that discontinuous recrystallization has occurred during the thermomechanical processing. It is known that discontinuous recrystallization can result in the preferred growth of grains of minor texture components, and these components dominate the final texture. ${ }^{[14]}$

On the other hand, considerable diffusion of alloying elements from the high-strength aluminum alloys into the Al $1050(\mathrm{H})$ occurs across the interface (Figure 4). Figure 4(a) shows the diffusion profile for $\mathrm{Cu}$ and $\mathrm{Mg}$ in the ALH19-T6 laminate, which are the main responsible elements of precipitation hardening in the Al 2024 alloy. Likewise, Figure 4(b) includes the Zn and $\mathrm{Mg}$ diffusion gradient across the interface in the ADH19-T6 laminate. Diffusion zones are formed mainly during processing and no influence of the T6 heat treatment was observed. It is worth noting that the diffusion zone width is slightly different for both laminates. In the ALH19-T6 laminate, $\mathrm{Cu}$ diffusion extends $\sim 30 \mu \mathrm{m}$ away from the interface position toward the Al 2024 alloy and $\sim 60 \mu \mathrm{m}$ toward the Al 

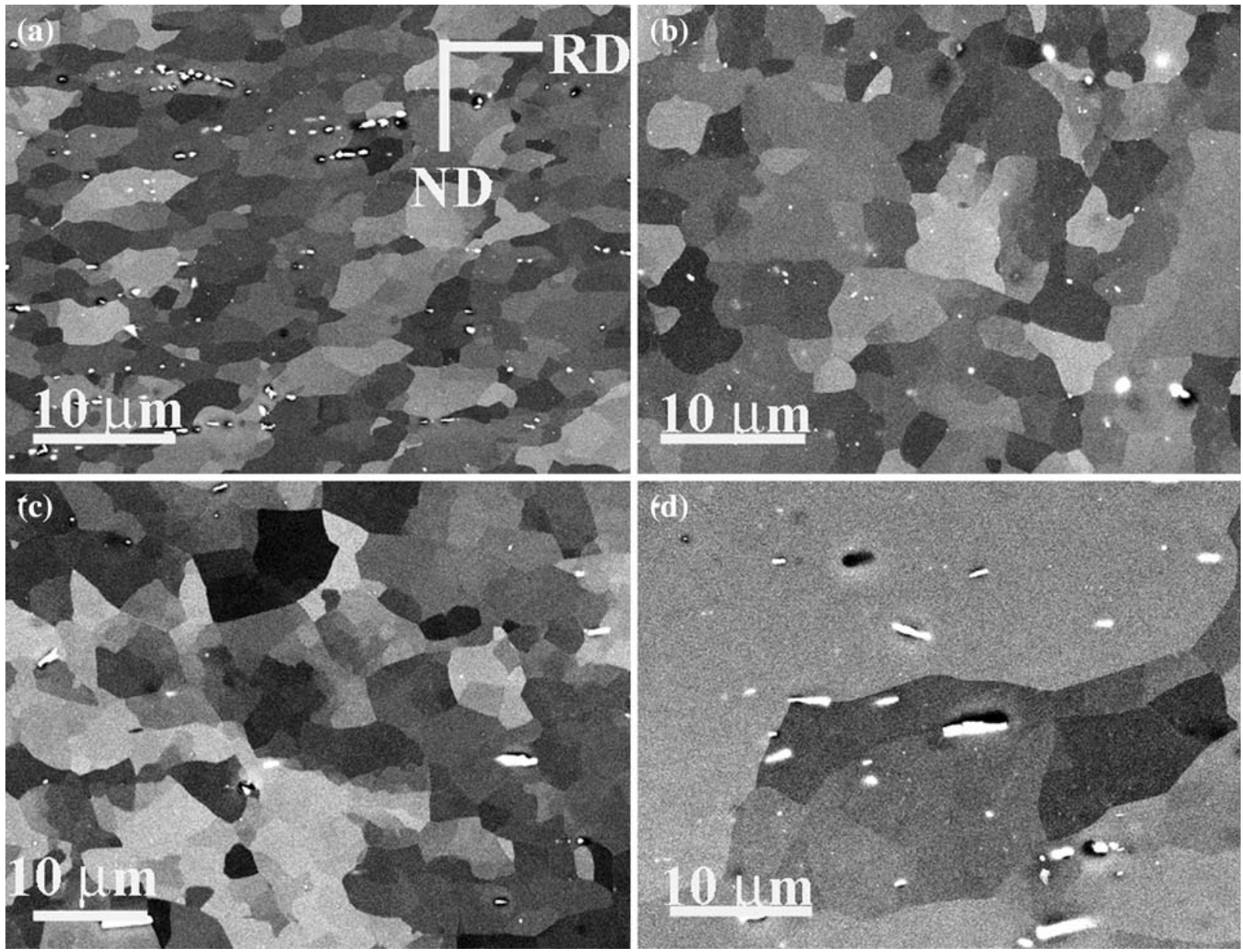

Fig. 2-Backscattered electron micrographs showing the Al 1050 microstructure in $(a)$ as-rolled ALH19 laminate, (b) ALH19-T6 laminate, (c) as-rolled ADH19 laminate, and (d) ADH19-T6 laminate.
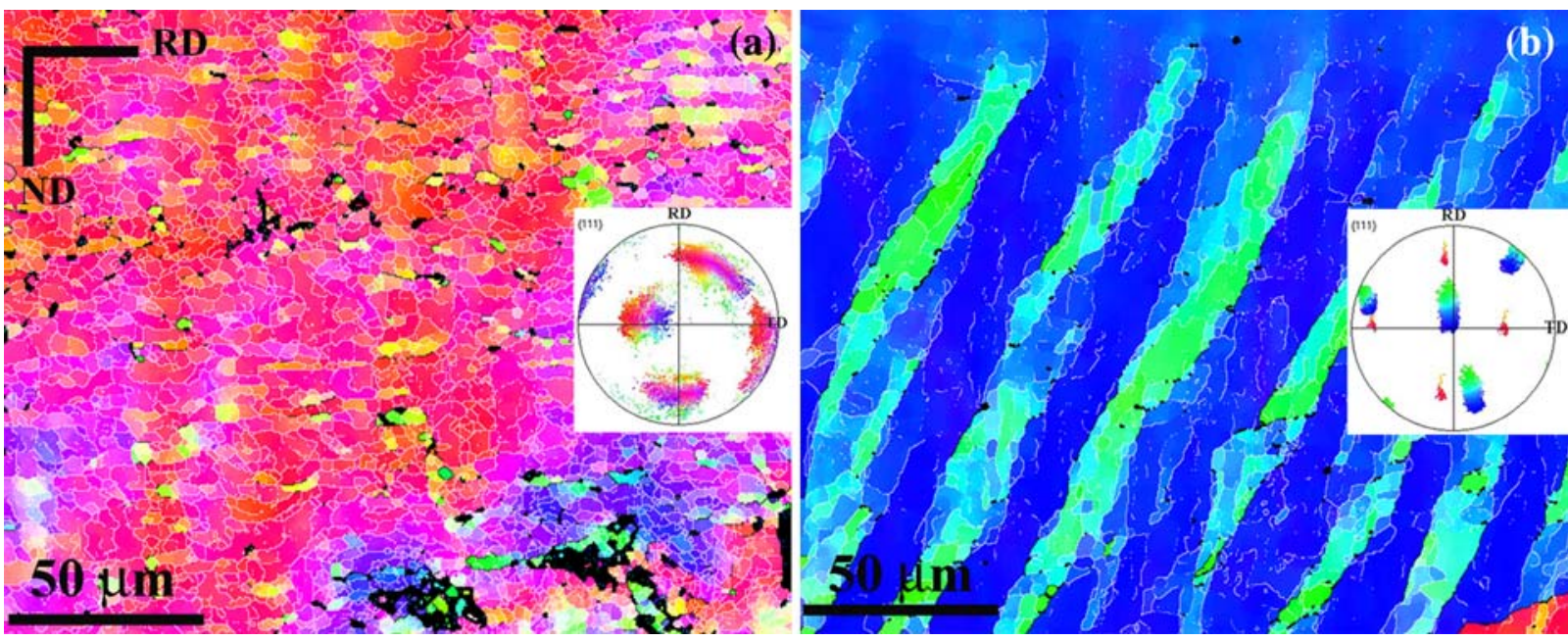

Fig. 3-EBSD maps showing the Al 1050 in as-rolled (a) ALH19 and (b) ADH19 laminates.

1050. In contrast, for the ADH19-T6 laminate, $\mathrm{Zn}$ diffusion starts $\sim 80 \mu \mathrm{m}$ toward the Al 7075 alloy and $70 \mu \mathrm{m}$ toward the $\mathrm{Al} 1050$. The $\mathrm{Mg}$ diffusion zone covers $\sim 75 \mu \mathrm{m}$ into the high-strength $\mathrm{Al} 2024$ and $\mathrm{Al}$ 7075 and $\sim 60 \mu \mathrm{m}$ into the Al 1050, for both laminates.

\section{B. Mechanical Tests}

1. Microhardness test

Figure 5 illustrates the microhardness profiles across two interfaces for each laminate. The data correspond to 


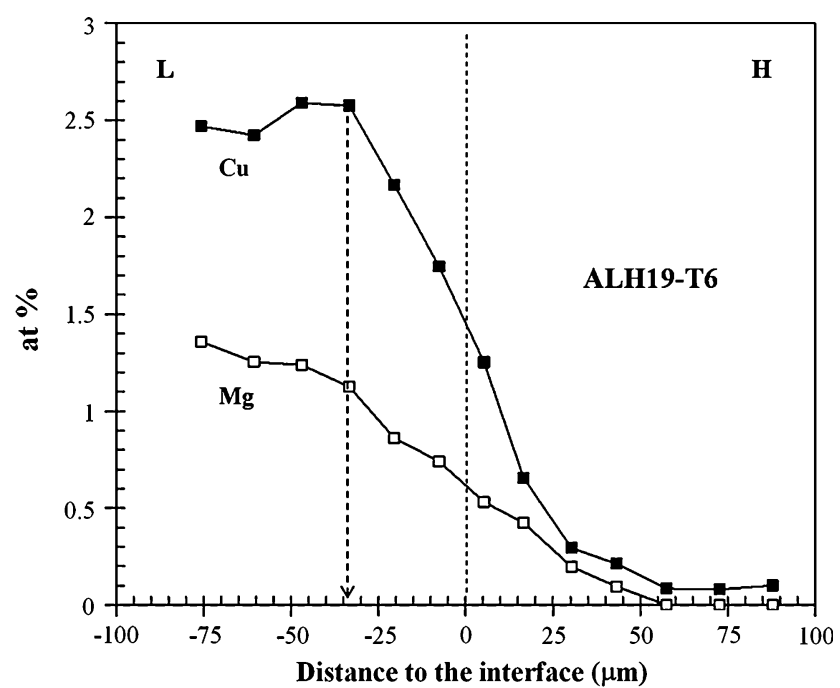

(a)

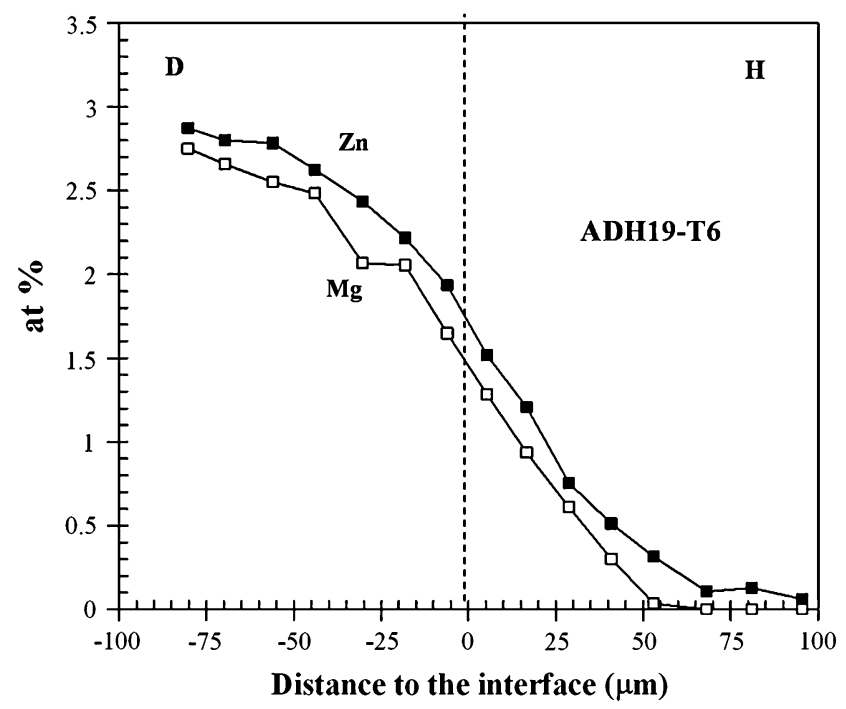

(b)

Fig. 4-Atomic percentage of alloying elements as a function of the distance to the interface in (a) ALH19-T6 $(\mathrm{Cu}$ and $\mathrm{Mg})$ and $(b)$ ADH19-T6 ( $\mathrm{Zn}$ and $\mathrm{Mg}$ ) laminates.

values obtained in various interfaces, because no difference between the external or internal interfaces was observed. The data present a trend similar to that given for the diffusion profiles (Figure 4) for both laminates. Thus, Figure 5 shows that the gradient of elements causes a decrease in microhardness values across the interface. In the ALH19-T6 laminate, similar to the $\mathrm{Cu}$ diffusion profile (Figure 4(a)), the microhardness gradient is approximately $30 \mu \mathrm{m}$ into the Al 2024 and approximately $60 \mu \mathrm{m}$ into the Al 1050 layer. On the other hand, in the ADH19-T6 laminate, the microhardness profile extends approximately $80 \mu \mathrm{m}$ into the Al 7075 and approximately $60 \mu \mathrm{m}$ toward the minimum hardness for the Al $1050(\mathrm{H})$. It can be observed for both laminates that the interfacial zone in the $\mathrm{Al} 1050$ has been largely strengthened by precipitation hardening. In addition, the horizontal dashed lines in Figure 5 indicate the mean microhardness value corresponding to

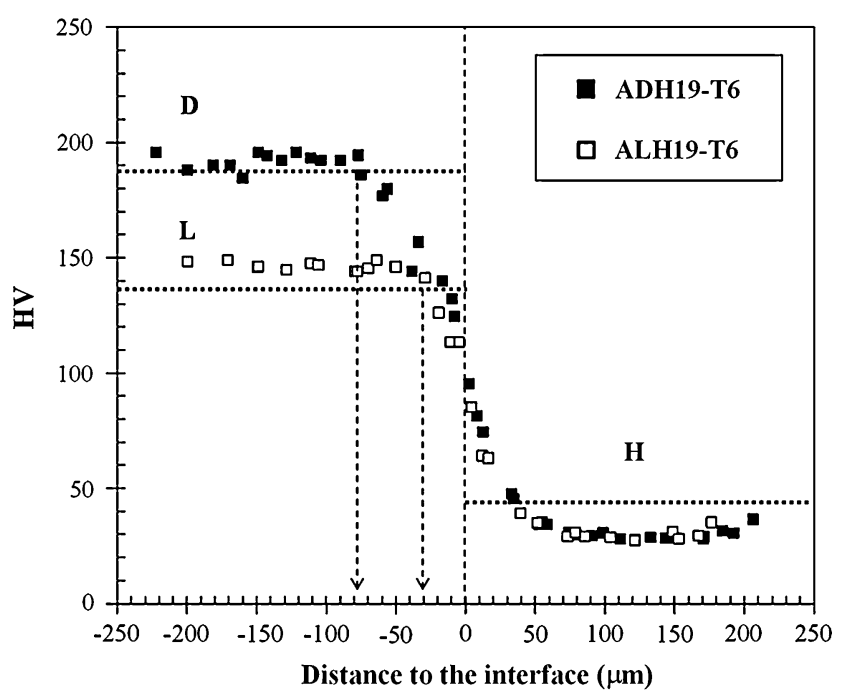

Fig. 5-Vickers microhardness of ALH19-T6 and ADH19-T6 laminates as a function of the distance to the interface.

the as-received Al 2024 (L: $138 \mathrm{HV}$ ) and $\mathrm{Al} 7075$ (D: $188 \mathrm{HV}$ ) alloys and Al 1050 (H: $44 \mathrm{HV})$. After hot rolling, both Al 2024 and Al 7075 show higher microhardness values (146 and $192 \mathrm{HV}$, respectively) inside their corresponding laminates than in the as-received state, far from the interface. This is attributed to a finer microstructure as a consequence of the processing. In contrast, the Al 1050 shows lower microhardness in both laminates $(29 \mathrm{HV})$ than in the as-received condition $(44 \mathrm{HV})$, which is attributed to microstructure coarsening during the thermomechanical processing at high temperature and the elimination of dislocations.

\section{Torsion Tests}

Torsion tests have been widely used for evaluating the deformation behavior of materials at elevated temperatures. ${ }^{[15]}$ These tests offer the possibility of obtaining large deformation at high strain rates under conditions simulating those encountered in other forming processes, i.e., hot rolling. Therefore, the as-received Al 2024 and Al 7075 alloys were torsion tested to evaluate their mechanical behavior at the hot-rolling conditions employed for obtaining the studied laminates.

A selection of stress-strain curves obtained at different temperatures and a strain rate of $3.3 \mathrm{~s}^{-1}$ for the $\mathrm{Al} 2024$ and Al 7075 alloys are given in Figure 6. Each curve shows a rapid increase in the stress to a peak value $\left(\sigma_{p}\right)$ followed by a gradual softening to fracture. The peak stress increases with decreasing test temperature. It is likely that very fine particles start to precipitate dynamically during deformation of the samples, contributing, therefore, to the peak stress. ${ }^{[16]}$ Softening is due to the adiabatic heating of the samples during deformation and to dynamic recovery (DRV). The rapid softening to fracture observed especially at low temperature has been ascribed to solute depletion to precipitates, particle coalescence, and enhancement of DRV. ${ }^{[17]}$ The difference in peak stress between the two alloys is smaller at high torsion temperatures $\left(\sim 465^{\circ} \mathrm{C}\right)$ than at low torsion 


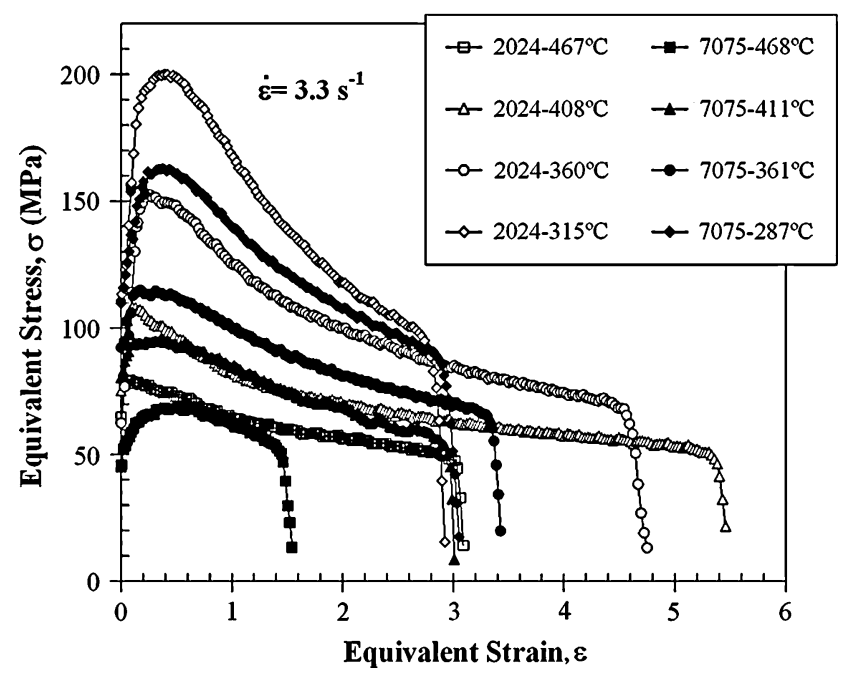

Fig. 6-Stress- $v s$-strain curves for as-received Al 2024 and Al 7075 alloys deformed in torsion. The deformation temperatures were in the range $287{ }^{\circ} \mathrm{C}$ to $468{ }^{\circ} \mathrm{C}$ and the strain rate was $3.3 \mathrm{~s}^{-1}$.

Table III. CVN Energy of As-Received and Laminate Materials

\begin{tabular}{lc}
\hline Material & CVN Energy $\left(\mathrm{kJ} / \mathrm{m}^{2}\right)$ \\
\hline $7075-$ T6 (D) & 62 \\
2024-T3 (L) & 178 \\
1050-H24 (H) & 333 \\
ALH19-T6 & 650 \\
ADH19-T6 & 1095 \\
\hline
\end{tabular}

temperatures $\left(\sim 300^{\circ} \mathrm{C}\right)$. In general, at all considered temperatures, the Al 2024 alloy shows higher peak stress than the Al 7075 alloy. In addition, the lowest fracture strain for both alloys is observed at the highest temperature of $465{ }^{\circ} \mathrm{C}$. Figure 6 illustrates the improvement in ductility with increasing test temperature for both alloys up to approximately $400{ }^{\circ} \mathrm{C}$. After this temperature, the ductility diminishes, which is probably associated with dissolution of elements in both alloys. In general, the Al 2024 shows higher ductility and strength at all test temperatures than the $\mathrm{Al} 7075$. The observed mechanical behavior for the aluminum alloys at high temperature is opposite to that at room temperature (Table II), at which the Al 7075 shows higher strength than the Al 2024 alloy.

\section{Charpy Test}

The results of the Charpy impact tests at room temperature are reported in Table III. The as-received materials and the two T6-treated laminates were tested in the crack arrester orientation. The Charpy V-notched $(\mathrm{CVN})$ energy average value for the monolithic materials Al 7075-T6 (D) and Al 2024-T3 (L) was 62 and $178 \mathrm{~kJ} / \mathrm{m}^{2}$, respectively, while for the Al $1050-\mathrm{H} 24(\mathrm{H})$, it was $333 \mathrm{~kJ} / \mathrm{m}^{2}$. The two laminate materials possess significantly higher impact energy than their corresponding constituent materials. The impact value of the ALH19-T6 laminate is 3.6 times higher than that of the

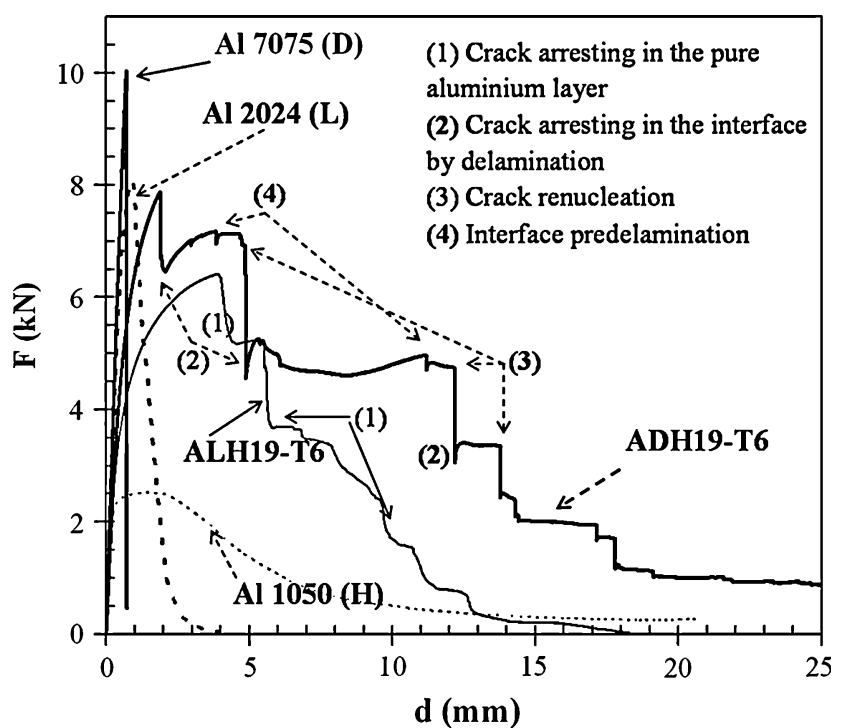

Fig. 7-Load-displacement curves obtained by three-point bend tests for the as-received materials and for the ALH19-T6 and ADH19-T6 laminates.

high-strength Al 2024 alloy and twice than the Al 1050. Likewise, the absorbed energy value for the ADH19-T6 laminate is 17.7 times higher than that for the Al 7075 alloy and 3.3 times higher than that for the Al 1050 . Therefore, the relative toughness increase compared to the constituent materials is more striking for the ADH19-T6 laminate, which is related to a different fracture mechanism that must be operating. This different damage tolerance behavior will be analyzed in depth by three-point bend tests.

\section{E. Three-point Bend Tests}

Three-point bend tests were conducted for a better understanding of the fracture mechanisms responsible for the high toughness of the hot-rolled laminates. Figure 7 shows load-displacement curves obtained from three-point bend tests for the monolithic as-received materials and for the two T6-heat-treated composite laminates in the crack arrester orientation. In this orientation, the crack is forced to pass through each layer sequentially, and it is the natural configuration for an aluminum panel in an airplane. Both monolithic Al 2024 alloy and Al 7075 alloy present high bending loads, 8 and $10 \mathrm{kN}$, respectively, but low ductility. In contrast, the aluminum presents lower strength $(2.5 \mathrm{kN})$ but excellent plasticity. As a result of processing, highintegrity laminate materials have been obtained with maximum bending loads of $6.3 \mathrm{kN}$ for the ALH19-T6 laminate and $7.9 \mathrm{kN}$ for the ADH19-T6 laminate. The ductility for both composite laminates is outstanding and is considerably higher for the ADH19-T6 laminate. The ductility increase is due to different intrinsic and extrinsic mechanisms of fracture that are operating. Thus, the figures clearly reveal differences between the fracture mechanisms of both laminate materials, which are a consequence of the properties of the constituent materials and their interfaces. The curve corresponding 
to the ALH19-T6 composite laminate shows first some strain hardening and then drops in load when cracking occurs in the less ductile Al 2024 layers, followed by gradual crack arrest in the Al 1050 layers (1) (in Figure 7) due to its high toughness (intrinsic toughening mechanism). The short plateaus in the curve $F-d$ indicate a high degree of bonding between the aluminum layers and plastic deformation of the remaining material, while the main crack is slowly propagating across the $\mathrm{Al} 1050$ layer until a new drop through the Al 2024 layer occurs. The slow and stepped crack propagation across the ALH19-T6 composite laminate compared to the Al 2024 alloy increases noticeably the area inside the $F$ - $d$ curve and thus the material toughness.

On the other hand, the ADH19-T6 laminate shows a first load drop, which coincides with cracking of the notched Al 7075 layer until the crack is deflected in the interface by delamination (2) (in Figure 7) (extrinsic fracture mechanism). The delamination mechanism is graphically characterized for subsequent strain hardening after crack arresting in the interface and plastic deformation of the remaining material until the next load drop occurs by crack renucleation (3) (in Figure 7). Moreover, long plateaus are characteristic of delamination. Delamination induces an increase in volume of the remaining material that experiences plastic deformation, increasing the curve plateaus and hence the toughness. Therefore, delamination makes the crack propagation in the next layer difficult, which must deform plastically until a new dominant crack is nucleated. Additionally, the curve corresponding to the ADH19-T6 laminate shows several small peaks in the plateaus (4) (in Figure 7) without large load drops, which may be associated with microdelamination in the next interface before the crack reaches it. This fracture mechanism, "interface predelamination, ${ }^{,[18]}$ is not observed for the ALH19-T6 laminate, indicating higher interface toughness in this laminate.

Figure 8 shows SEM micrographs at different magnifications of the crack propagation sequence in the ALH19-T6 (Figure 8(a)) and ADH19-T6 (Figures 8(b) and (c)) laminates during the bend test. In the ALH19T6 laminate, the main crack initiated at the notch tip in a Al 1050 layer (micrograph not included), and then propagated through this and the next Al 2024 layer, until being arrested at the Al 1050 layer by an intrinsic mechanism. This is due to the high bonding between layers in this laminate (avoiding delamination) and to the inherent toughness of the Al 1050 layer, which offers high resistance to the crack growth (Figure 8(a)). In addition, while the main crack is being retarded at the Al 1050 layer, another extrinsic fracture mechanism, named "crack bridging," occurs. According to this mechanism, different new cracks reinitiate in the next $\mathrm{Al}$ 2024 layer (L) before the main crack reaches it, because its bend failure strain is reached. Thus, in this extrinsic toughening mechanism, unbroken ligaments in the $\mathrm{Al}$ 1050 and Al 2024 alloys in the wake of the crack prevent catastrophic crack propagation, due to the bridging of the crack. Crack growth requires stretching of the bridging ligaments with additional energy absorption. On the other hand, in the ADH19-T6 laminate (Figure 8(b)), the crack initiated at the notch tip located
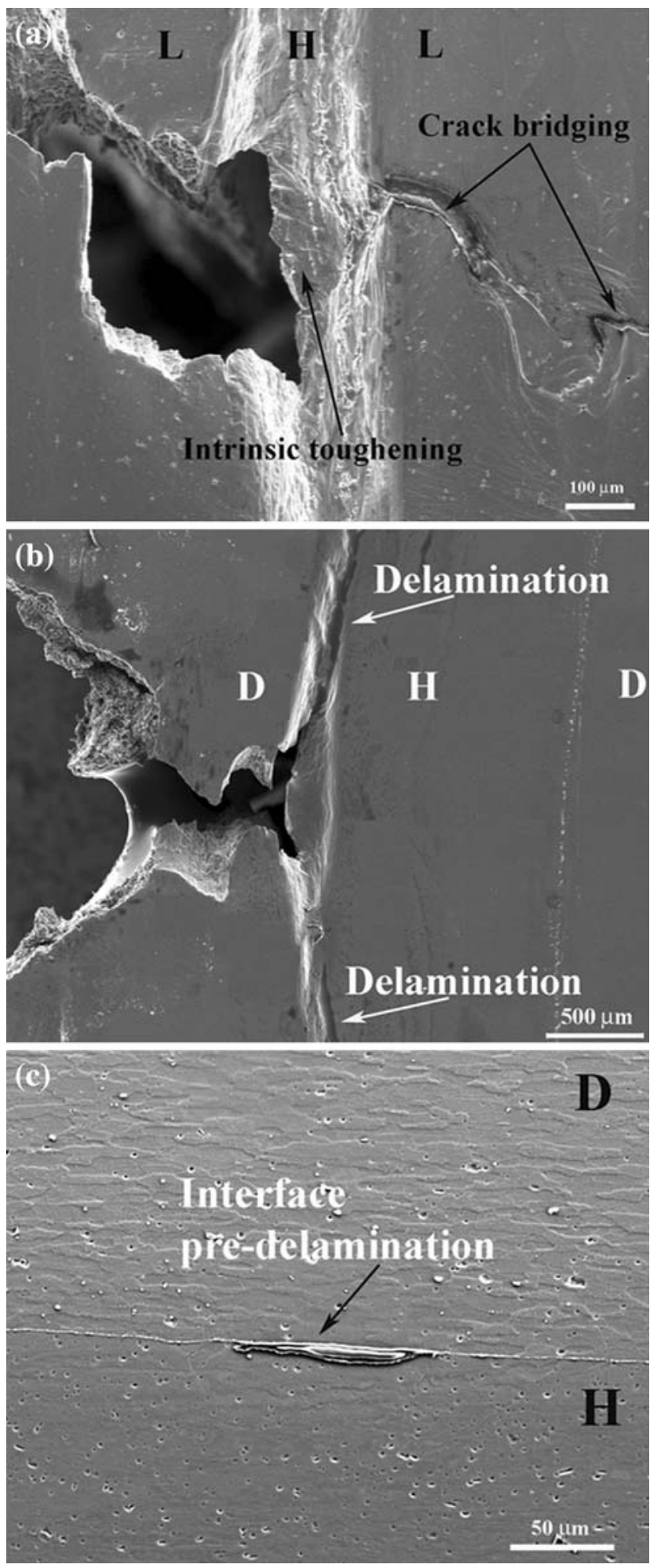

Fig. 8- SEM micrographs of fractured samples from bend tests showing different fracture mechanisms: (a) ALH19-T6 and $(b)$ and (c) ADH19-T6.

in an $\mathrm{Al} 7075$ layer. Delamination in the interfaces between layers can be observed being the main fracture mechanism responsible for impact toughness improvement. In addition, Figure 8(c) shows a short 

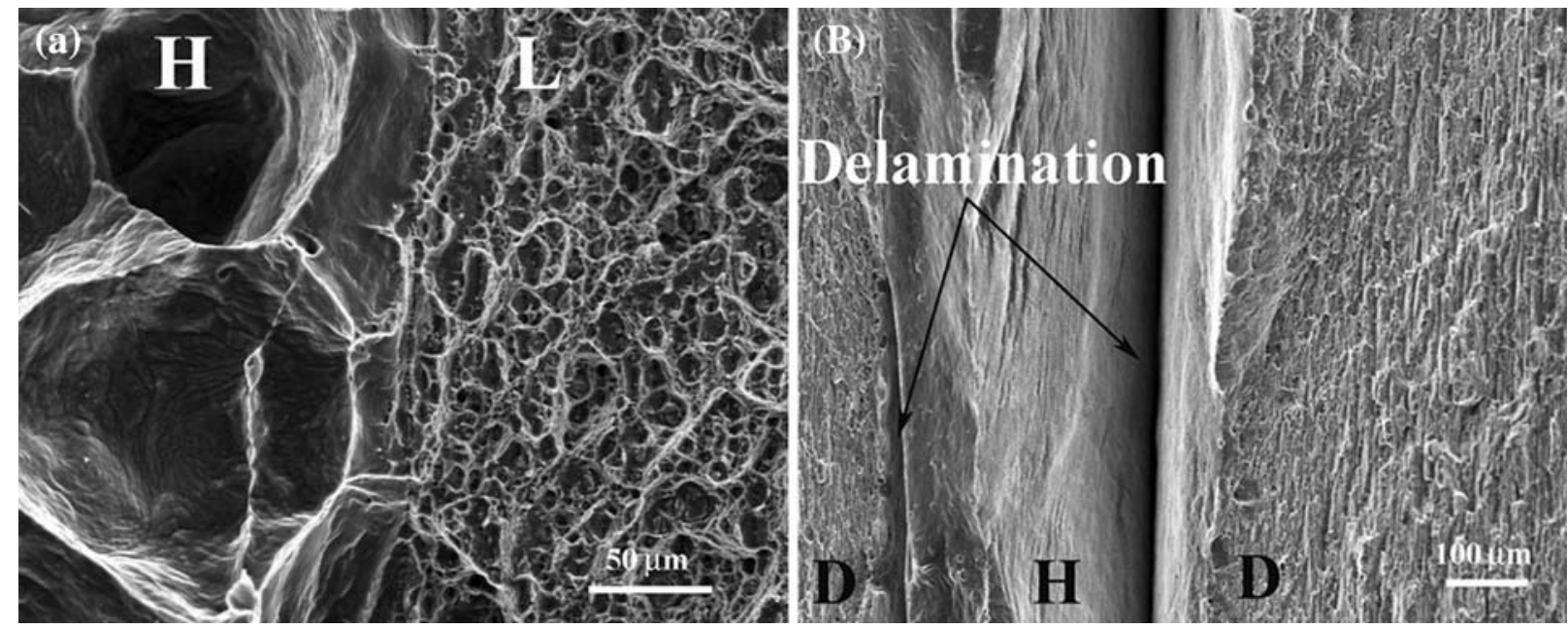

Fig. 9-SEM micrographs showing fractured surfaces from bend-tested samples in the crack divider orientation: (a) ALH19-T6 and (b) ADH19-T6.

delamination in an internal interface, which has been named an "interface predelamination" mechanism. Under this fracture mechanism, the next interface is delaminating locally before the main crack reaches it, due to the stresses that the interface encounters during the bending test. This mechanism results in a reduction and redistribution of the local stress and warrants further delamination and renucleation of a new crack, thus improving ductility and toughness.

Finally, Figure 9 shows SEM micrographs of the ALH19-T6 (Figure 9(a)) and ADH19-T6 (Figure 9(b)) samples after the bend test in the crack divider orientation. In this orientation, the initial notch tip intersects all the layers of the test sample and, therefore, the crack front encounters all the interfaces simultaneously. It can be clearly observed that there is different fracture behavior for both laminates. Figure 9(a), corresponding to the ALH19-T6 fracture surface, shows a good bonding between the aluminum layers without delamination. The Al 1050 fracture surface shows large voids as a result of the coarse grains arising from the high temperatures developed during the thermomechanical processing. The Al 2024 fracture surface shows voids $\sim 10$ to $15 \mu \mathrm{m}$ in diameter, which are smaller than the grain size in the as-received alloy. On the other hand, the micrograph of the ADH19-T6 sample (Figure 9(b)) shows debonding of the aluminum layers, indicating that the interfaces are less tough. Macroscopically brittle failure is evident in the Al 7075 layers of the ADH19-T6 laminate. In addition, extensive necking and deformation bands are apparent in the $\mathrm{Al} 1050$ layers.

\section{F. Shear Test}

To characterize precisely the mechanical properties of interfaces, which are mainly responsible for the fracture mechanisms and the damage tolerance improvement observed, shear tests along them have been performed (Figure 10). During testing, all interfaces failed through the bonded region because the shear tests were designed

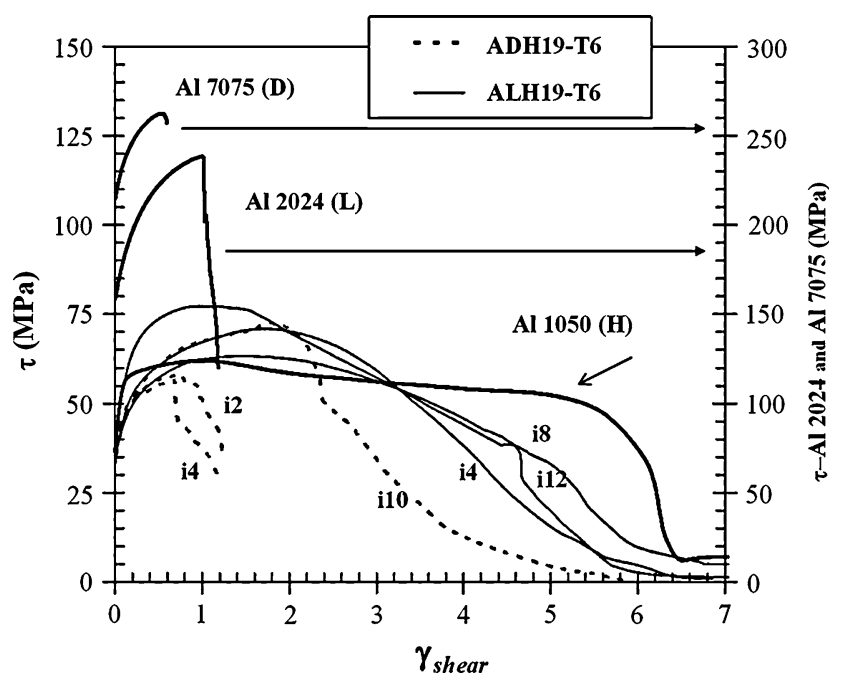

Fig. 10 - Shear tests at the interfaces of the ALH19-T6 and ADH19T6 laminates compared with as-received aluminum alloys.

to concentrate the load along the bond plane (scheme in Reference 18). During this test, failure is produced through the weakest component of the bonding, i.e., if the interfacial strength is low, failure is produced across the interface. On the contrary, if the interfacial strength is high, cohesive failure is located in the Al 1050 adjacent to the interface. The interfaces in the laminates are assigned numbers to indicate their location in the laminate (for example, i4 means the fourth interface from the surface). For comparison, monolithic as-received $\mathrm{Al} 1050(\mathrm{H}), \mathrm{Al} 2024(\mathrm{~L})$, and $\mathrm{Al} 7075$ (D) alloys are also included. The maximum shear stress of the Al 2024 and $\mathrm{Al} 7075$ alloys is 232 and $261 \mathrm{MPa}$, respectively (scaled on the right ordinate axis), and the plastic shear deformation is 1.2 and 0.6 , respectively. In contrast, the maximum shear stress of the Al 1050 is only $58 \mathrm{MPa}$, but it is much more ductile $\left(\gamma_{\text {plast.max }}=6.5\right)$. Regarding the ALH19-T6 laminates, 
their interfaces are ductile, having elongation to failure values $\left(\gamma_{\text {plast.max }}\right.$ at $\sim 6$ ) similar to the monolithic Al 1050 . Moreover, the shear strength is slightly higher than for the Al 1050, which may be attributed to the effect of plastic constraint ${ }^{[19]}$ between Al 2024 layers and the higher strength close to the interface by element diffusion and subsequent precipitation hardening. Failure occurred in the Al $1050(\mathrm{H})$ next to the interface. Thus, the bond strength exceeds the fracture strength of the weaker component (Al 1050), an indication of a high degree of bonding. On the other hand, the interfaces of the ADH19-T6 laminate show slightly less shear strength than those of the ALH19-T6 laminate or the Al 1050 and, in general, lower ductility ( $\gamma_{\text {plast.max }}$ at $\left.\sim 1\right)$, with an interfacial failure between the aluminum layers. The locus of failure indicates that interfaces are the component with the lower toughness of the ADH19 laminate composite and are the location at which the crack propagates more easily. This is consistent with the delamination observed under bend loads increasing the toughness by an extrinsic crack deflection mechanism.

\section{DISCUSSION}

Hot roll bonding can be used as a deformation and bond method to produce light multilayer aluminum materials with great relevance for technical applications. However, the bonding of layers and the fracture mechanisms are a strong function of the constituent materials and their mechanical properties at the temperatures reached during the processing. In this study, two aluminum multilayer laminates with different constituent materials have been hot roll bonded using similar deformation and temperature paths, showing dissimilar fracture mechanisms. Both laminates present improved impact toughness with respect to the constituent materials.

\section{A. Microstructure}

The microstructure evolution for the Al 1050 constrained between the high-strength Al 2024 and Al 7075 alloys present in the multilayer laminates has been analyzed both by backscattered electron microscopy and by EBSD maps (Figures 1 through 3). As a starting point, a change in the texture of the Al 1050 layers for both laminates in the as-rolled state has been observed, indicating that discontinuous recrystallization has occurred during the thermomechanical processing. Therefore, the observed microstructure in both laminates is the result of the processing conditions and the mechanical properties of the high-strength alloys that constrain the Al 1050 layer. After the rolling process and before any thermal treatment, the Al 1050 constrained between Al 2024 in the as-rolled ALH19 laminate showed a microstructure consisting of homogeneously distributed LABs (subgrains). On the other hand, for the Al 1050 in the as-rolled ADH19 laminate and constrained between high-strength Al 7075 layers, a regular array of parallel bands was observed. These bands of elongated cells are associated with low strains in rolled aluminum and nickel alloys. ${ }^{[20]}$ The occurrence of deformation banding is dependent on the initial grain size and it predominates mainly in coarse-grained materials. It is also seen that the orientation of the matrix within these bands is similar. In contrast, the alignment of the subgrains or dislocation cells of the Al 1050 in the ALH19 laminate with respect to the rolling plane (Figure 3(a)) is associated with high strain. It is worth noting that the large strain experimented during each rolling pass by the Al 1050 constrained between the Al 2024 alloy, presenting higher strength at the processing temperatures than the Al 7075 alloy (Figure 6), is responsible for the homogenous (sub)grain microstructure observed.

In addition, "abnormal" grain growth was noted in the Al 1050 of the as-rolled ADH19 laminate and after T6 treatment. This abnormal grain growth may be attributed to nonequilibrium grain boundaries giving enhanced boundary mobility. ${ }^{[21]}$ On the contrary, if the mean misorientation between (sub)grains is large, discontinuous growth within the microstructure becomes less extensive. For misorientations greater than $10 \mathrm{deg}$, a microstructure that is stable against discontinuous growth results, and only normal grain growth is found. In this regard, EBSD maps corresponding to Al 1050 in the as-rolled ALH19 laminate (Figure 3(a)) showed higher subgrain misorientation than in the as-rolled ADH19 laminate (Figure 3(b)).

Thus, it is our contention that during the hot roll processing, the Al 1050 constrained between Al 2024 in the ALH19 laminate has been subjected to higher stresses (Figure 6). As a consequence, a finer and more homogeneous microstructure through successive rolling passes has developed, remaining more stable to abnormal grain growth during the T6 treatment.

During the processing at elevated temperatures, an exchange of alloying elements occurs through the formed interface. Simultaneously, the Al 1050 extrudes across the crack openings in the alumina layer into the high-strength aluminum alloys. The final interface is made up of oxide fragments and newly generated metal surface. Therefore, concentrations gradually change over the interface, creating an area of age-hardenable compositions. It is mainly $\mathrm{Cu}, \mathrm{Mg}$, and $\mathrm{Zn}$ from the high-strength aluminum alloys that diffuse into the $\mathrm{Al}$ 1050 layers (Figure 4). A minimum element concentration is required for the formation of effective hardening precipitates, $\theta\left(\mathrm{CuAl}_{2}\right)$ and $S\left(\mathrm{Al}_{2} \mathrm{CuMg}\right)^{[22]}$ of the $\mathrm{Al}$ 1050 layers in the ALH19-T6 laminate, and $\eta^{\prime}$ $\left(\mathrm{MgZn}_{2}\right)^{[23]}$ in the ADH19-T6 laminate. The width of these diffusion areas was determined by microanalysis and hardness measurements (Figure 5). The ADH19 laminate exhibits the widest diffusion zone and the ALH19 laminate the narrowest. The diffusion regions spread within the same range as the results from the microhardness measurements (Figure 5), in which a significant hardness gradient is observed and extends the same distance as the element diffusion gradient from the interface. The different diffusion extension between $\mathrm{Zn}$ and $\mathrm{Cu}$ across the interface is attributed to a lower amount of dissolved $\mathrm{Cu}$ at the processing temperature 
$\left(465^{\circ} \mathrm{C}\right)$. Both elements present similar atomic size ( $\mathrm{Cu}$ : $0.128 \mathrm{~nm}$; $\mathrm{Zn}: 0.133 \mathrm{~nm})$, smaller than that of $\mathrm{Al}$ $(0.143 \mathrm{~nm}) .^{[24]}$ Therefore, similar activation energy for diffusion in aluminum $\left(\mathrm{Cu}: 130.7 \mathrm{~kJ} / \mathrm{mol} ;{ }^{[25]} \mathrm{Zn}\right.$ : $121.3 \mathrm{~kJ} / \mathrm{mol}^{[26]}$ ) and a similar diffusion distance for the same processing path would be expected. However, $465{ }^{\circ} \mathrm{C}$ is the solution temperature for the $\mathrm{MgZn}_{2}$ precipitate in the Al 7075 alloy, but it is low to dissolve rich $\mathrm{Cu}$ precipitates in the Al 2024 alloy. Thus, it is reasonable to conclude that the difference in the diffusion behavior between $\mathrm{Zn}$ and $\mathrm{Cu}$ in the corresponding laminate is due to a lower amount of $\mathrm{Cu}$ in solid solution. Finally, a higher Zn diffusion extension gives rise to a wider precipitation hardened zone, which will affect the interface fracture mechanism.

\section{B. Mechanical Properties}

The Al 2024 alloy tested by hot torsion exhibited higher peak stress at all considered temperatures, which are those corresponding to roll bonding, than the $\mathrm{Al}$ 7075 alloy (Figure 6). Thus, the higher flow stress of the Al 2024 suggests an increased stress on the interfaces in the ALH19 laminate, determining their mechanical behavior. The degree of bonding for this laminate should be higher than for the ADH19 laminate, because higher pressures have to be applied during processing, considering the higher peak stress values of the Al 2024. This has been checked by bend and shear tests, as shown in Figures 7 through 10. Furthermore, the Al 1050 constrained between Al 2024 has a finer subgrain size, because this parameter is inversely proportional to the applied stress (Figure 3 ).

In addition, the lower relative increase in absorbed energy value for the ALH19-T6 laminate during the Charpy test (Table III) with respect to its constituent materials compared to that for the ADH19-T6 laminate is attributed to stronger interlayer bonds. The degree of bonding also influences the shape of the bend and the shear curves (Figures 7 and 10). The bend force displacement curve of the strong-bonded ALH19-T6 laminate is very different from that of the ADH19-T6 laminate (Figure 7). The stepped shape with short plateaus of the bend curve corresponding to the ALH19-T6 laminate indicates slow and progressive crack propagation across the laminate; it is a consequence of the high degree of bonding. In contrast, the long plateaus associated with delamination observed for the ADH19-T6 laminate increases the ductility of the material, due to the strain hardening and plastic deformation of the remaining material after crack arresting in the interface. This raises notably the total energy absorbed and thus the material toughness. Therefore, if energy absorption is the goal, strong bonds are not desirable and controlled delamination is preferred.

The physical mechanism of toughening for the presented laminates can be deduced from the results mentioned. The main contribution to the toughening mechanism for the ALH19 laminate is the intrinsic toughness of its constituent materials, due to the absence of delamination as a consequence of the high interfacial toughness. In this sense, the high toughness of the Al 1050 delays crack propagation. In contrast, the low interfacial toughness for the ADH19 laminate favors extrinsic toughening mechanisms, such as delamination and crack renucleation. Accordingly, ductile layers of Al 1050 must be work hardened and plastic strained until a new crack is renucleated. Thus, the work of deformation contributes to the overall toughness. In addition, small load drops in the plateaus of bending curves for ADH19-T6 laminate indicate microdelaminations in the interfaces before the main crack reaches the interface. ${ }^{[18]}$ This additional mechanism warrants extensive delaminations and, therefore, large amounts of plastic deformation are necessary to induce a new crack in the following layer.

Finally, shear tests also give valuable information on the mechanical characterization of the laminates. It should be noted that shear strength requirements for bonds in aircraft structures are generally much lower, 10 to $20 \mathrm{MPa}$, than those observed in the present work, ${ }^{[27]}$ which shows the lowest shear strength value for some interfaces in the ADH19-T6 laminate equal to $55 \mathrm{MPa}$. The shear toughness of the interfaces was measured as the area under the $F-d$ shear curve; it was found to be between 98 and $116 \mathrm{~kJ} / \mathrm{m}^{2}$ for the ALH19-T6 laminate, being similar to that of its constituent materials (101 and $121 \mathrm{~kJ} / \mathrm{m}^{2}$ for the Al 2024 and Al 1050, respectively). On the other hand, the ADH19-T6 presents low tough interfaces, with values ranging between 21 and $24 \mathrm{~kJ} / \mathrm{m}^{2}$ (i2 and i4, respectively) and $76 \mathrm{~kJ} / \mathrm{m}^{2}$ (i10), which is considerably lower than the shear toughness of its constituent materials ( $88 \mathrm{~kJ} / \mathrm{m}^{2}$ for the Al 7075 alloy). Previous results ${ }^{[28,29]}$ have predicted that the crack likely goes through the interface if the interfacial toughness exceeds approximately one-fourth the toughness of the material across the interface. Therefore, the interfacial toughness values measured by the shear test for the ADH19 laminate indicate the presence of interfaces prone to delamination, which are responsible for the high impact toughness of the laminate.

It can be concluded that this study reveals the important role of the interface mechanical properties in optimizing the impact toughness of rolled multilayer materials.

\section{CONCLUSIONS}

Two multilayer materials based in alternate highstrength aluminum alloys (A1 2024 and Al 7075) and Al 1050 were successfully processed by hot roll bonding.

Both laminates were found to exhibit outstanding improvement in impact fracture toughness over asreceived constituent materials. The differences in the fracture mechanisms of the two laminates, under bend and Charpy tests at room temperature, depend mainly on the mechanical strength of the constituent materials at the considered processing temperatures. Accordingly, the higher strength of the Al 2024 alloy at the rolling temperatures exerts higher pressure on the bond interface between layers during processing, which leads to tougher interfaces with a high degree of bonding, and 
favors intrinsic fracture mechanisms. On the contrary, for similar imposed processing, the lower strength of the Al 7075 alloy at high temperatures results in interfaces prone to delamination, increasing considerably the laminate toughness by extrinsic mechanisms such as crack deflection and subsequent crack renucleation.

\section{ACKNOWLEDGMENTS}

Financial support from CICYT (Project Nos. MAT2003-01172 and MAT2006-11202) is gratefully acknowledged. One of the authors (CMC-J) thanks the Spanish National Research Council (CSIC) (Madrid, Spain) for a I3P contract. The authors also thank L. del Real-Alarcón for the welding work, F.F. González-Rodríguez for assistance during hot rolling, and J. Chao-Hermida for assistance with the Charpy impact test. Finally, a special mention is made in memory of P.J. González-Aparicio, for his help and assistance with electron microscopy over many years.

\section{REFERENCES}

1. B.A. Movchan and F.D. Lemkey: Mater. Sci. Eng., A, 1997, vol. 224 , pp. $136-45$

2. D. Wang and Z.Y. Ma: J. Alloys Compd., 2009, vol. 469, pp. 44550

3. S. Bueno and C. Baudín: Key Eng. Mater., 2007, vol. 333, pp. 1726.

4. H. Danesh Manesh and H. Sh. Shahabi: J. Alloys Compd., 2009, vol. 476, pp. 292-99.

5. C.M. Cepeda-Jiménez, M. Pozuelo, O.A. Ruano, and F. Carreño: Mater. Sci. Eng., A, 2008, vol. 490, pp. 319-27.

6. M. Pozuelo, F. Carreño, and O.A. Ruano: Compos. Sci. Technol., 2006, vol. 66, pp. 2671-76.

7. G. Heness, R. Wuhrer, and W.Y. Yeung: Mater. Sci. Eng., A, 2008, vols. 483-484, pp. 740-42.

8. M.Z. Quadir, A. Wolz, M. Hoffman, and M. Ferry: Scripta Mater., 2008, vol. 58, pp. 959-62.
9. C.M. Cepeda-Jiménez, M. Pozuelo, J.M. García-Infanta, O.A. Ruano, and F. Carreño: Mater. Sci. Eng., A, 2008, vol. 496, pp. 133-42.

10. M. Carsí, F. Peñalba, O.A. Ruano, and O.D. Sherby: Metall. Mater. Trans. A, 1997, vol. 28A, pp. 1913-20.

11. D.S. Fields, Jr. and W.A. Backofen: Proc. ASTM, 1957, vol. 57, pp. $1259-72$.

12. C.M. Cepeda-Jiménez, R.C. Alderliesten, O.A. Ruano, and F. Carreño: Compos. Sci. Technol., 2009, vol. 69, pp. 343-48.

13. G.E. Dieter: Mechanical Metallurgy, SI Metric, London, United Kingdom, 1988, pp. 12-15.

14. F.J. Humphreys and M. Hatherly: Recrystallization and Related Annealing Phenomenon, 2nd ed., Elsevier, Oxford, United Kingdom, 2004, pp. 68-74.

15. A. Fernández-Vicente, M. Carsí, F. Peñalba, F. Carreño, and O.A. Ruano: Z. Metallkd., 2003, vol. 94, pp. 922-29.

16. B. Verlinden, P. Wouters, H.J. McQueen, E. Aernoudt, L. Delaey, and S. Cauwenberg: Mater. Sci. Eng., A, 1990, vol. 123, pp. 22937.

17. E. Cerri, E. Evangelista, A. Forcellese, and H.J. McQueen: Mater. Sci. Eng., A, 1995, vol. 197, pp. 181-98.

18. C.M. Cepeda-Jiménez, M. Pozuelo, J.M. García-Infanta, O.A. Ruano, and F. Carreño: Metall. Mater. Trans. A, 2009, vol. 40, pp. 69-79.

19. M. Bannister and M.F. Ashby: Acta Metall. Mater., 1991, vol. 39, pp. $2575-82$

20. P.J. Hurley and F.J. Humphreys: Acta Mater., 2003, vol. 51, pp. 1087-1102

21. C.Y. Yu, P.L. Sun, P.W. Kao, and C.P. Chang: Mater. Sci. Eng., A, 2004, vol. 366, pp. 310-17.

22. C. Badini, F. Marino, and E Verné: Mater. Sci. Eng., A, 1995, vol. 191, pp. 185-91.

23. F. Viana, A.M.P. Pinto, H.M.C. Santos, and A.B. Lopes: J. Mater. Process. Technol., 1999, vols. 92-93, pp. 54-59.

24. W.D. Callister: Materials Science and Engineering: An Introduction, 3rd ed., John Wiley \& Sons, Inc., New York, NY, 1994.

25. B. Huang and Z. Zheng: Scripta Mater., 1998, vol. 38, pp. 611-16.

26. R. Galler and H. Mehrer: Mater. Sci. Eng., A, 2000, vols. 294-296, pp. 693-96.

27. Y. Huang, N. Ridley, F.J. Humphreys, and J.-Z. Cui: Mater. Sci. Eng., $A$, 1999, vol. 266, pp. 295-302.

28. J.W. Hutchinson: A Short Course on: The Integrity of Thin Films and Multilayers, National University of Singapore, Singapore, 1997, pp. 21-34.

29. F. Carreño, M. Pozuelo, J.A. Jiménez, and O.A. Ruano: Mater. Sci. Forum, 2007, vols. 539-543, pp. 901-06. 